\title{
Reflexos da hospitalização da criança na vida do familiar acompanhante
}

\author{
Reflections of child hospitalization in the life of the familiar attender \\ Reflexiones de la hospitalización del niño en la vida del acompañante familiar
}

\section{Leidiene Ferreira Santos', Lizete Malagoni de Almeida Cavalcante Oliveira", Maria Alves Barbosa", Karina Machado Siqueira"', Myrian Karla Ayres Veronez Peixoto ${ }^{\text {IV }}$}

\author{
' Universidade Federal de Goiás, Programa de Pós-Graduação em Ciências da Saúde (Doutoranda). Goiânia-GO, Brasil. \\ " Universidade Federal de Goiás, Faculdade de Enfermagem. \\ Programa de Pós-Graduação em Enfermagem. Goiânia-GO, Brasil. \\ "' Universidade Federal de Goiás, Programa de Pós-Graduação em Enfermagem (Doutoranda). Goiânia-GO, Brasil. \\ IV Universidade Federal de Goiás, Programa de Pós-Graduação em Enfermagem (Mestranda). Goiânia-GO, Brasil.
}

Submissão: 19-05-2011 Aprovação: 06-06-2013

\section{RESUMO}

Pesquisa convergente assistencial, que objetivou investigar os reflexos da hospitalização da criança na vida do familiar acompanhante. Foi realizada em um hospital localizado em Goiânia-GO, em que acompanhantes de crianças hospitalizadas participaram de um grupo de apoio. A coleta de dados ocorreu de fevereiro a julho de 2010, por meio de gravação e transcrição das sessões grupais; para analisar os fatos e fenômenos vividos no grupo, foi usada a análise temática. Os resultados encontrados fornecem aos profissionais de saúde subsídios que permitem compreender o quão é complexa a experiência de "ter" e "conviver" com criança da família em situação de doença e hospitalização. Concluímos que essa experiência compromete o relacionamento familiar, a saúde física e mental, e a manutenção da rede social do acompanhante.

Descritores: Criança Hospitalizada; Enfermagem; Saúde da Família.

\section{ABSTRACT}

This is an assistance convergent research, which aimed to investigate the effects of child's hospitalization in the companion family life. It was performed in a hospital located in Goiania-GO, Brazil, where parents of hospitalized children participated in a support group. Data collection occurred from 2010 February to July, through the recording and transcription of group sessions; to analyze the facts and phenomena experienced in the group, it was used the thematic analysis. The results provide subsidies for health professionals that allow them to understand how complex is the experience of "having" and "live" with a family child in situation of illness and hospitalization. We conclude that this experience affects family relationships, mental and physical health, and the maintenance of the social networking of the companion.

Key words: Child Hospitalized; Nursing; Family Health.

\section{RESUMEN}

Pesquisa convergente asistencial, que tuvo como objetivo investigar las consecuencias de la hospitalización de niños en la vida del familiar acompañante. He sido realizada en un hospital ubicado en Goiânia-GO, Brasil, donde los acompañantes de los niños hospitalizados fueron invitados a participar de un grupo de apoyo. Los datos fueron recolectados de febrero a julio de 2010, a través de grabación y transcripción de las sesiones del grupo, y para trabajar con los factos e fenómenos vividos en el grupo, he sido usada el análisis temática. Los resultados encontrados ofrecen para los profesionales de la salud subsidios que les permiten comprender la complejidad de la experiencia de "tener" y "vivir" con un niño de la familia en situación de enfermedad y hospitalización. Llegamos a la conclusión de que esta experiencia afecta a la relación familiar, la salud física y mental, y al mantenimiento de la red social del familiar acompañante.

Palabras clave: Niño Hospitalizado; Enfermería; Salud de la Familia. 


\section{INTRODUÇÃO}

A doença e hospitalização da criança alteram a dinâmica familiar e levam a família a sentimentos e emoções que variam entre tristeza, medo, pena, culpa e impotência, entre outros $^{(1-5)}$. Nesse cenário, destacamos o papel da pessoa que acompanha a criança durante sua hospitalização, pois é ela quem vivencia a dificuldade de sair do ambiente familiar para um mundo novo, permeado por incertezas e insegurança ${ }^{(5-6)}$.

No hospital, o acompanhante vivencia experiências que, na maioria das vezes, são negativas, em razão do ambiente hostil, das ameaças reais e imaginárias, da ruptura familiar ou da perda/redução da autonomia da família em relação à criança. Essas situações colaboram para intensificar o sentimento de fragilidade do acompanhante ${ }^{(7)}$.

Também é importante destacar que os longos períodos de internação da criança, as visitas recorrentes ao hospital, o repouso prejudicado em decorrência da preocupação com a saúde da criança e das responsabilidades assumidas nesse processo e as dificuldades financeiras e de acesso ao serviço de saúde, produzem grande desgaste físico e emocional ao acompanhante ${ }^{(8-9)}$.

Assim, essa pesquisa se propôs a investigar os reflexos da hospitalização da criança na vida do acompanhante, visando contribuir para melhorar a assistência prestada ao acompanhante da criança hospitalizada. Os resultados do estudo poderão servir de subsídio para o planejamento e desenvolvimento de intervenções dirigidas ao atendimento das reais necessidades do acompanhante, pelas equipes de saúde, ajudando-o no enfrentamento da situação de "ter" e de "conviver" com uma criança em situação de doença e hospitalização.

\section{METODOLOGIA}

Trata-se de uma investigação descritiva e exploratória do tipo convergente assistencial. A opção por essa modalidade de pesquisa se deu porque nela as ações de assistência são incorporadas ao processo de pesquisa e os processos de pesquisa são incorporados às ações assistenciais, permitindo introduzir inovações no cuidado de enfermagem ${ }^{(10)}$.

O estudo foi desenvolvido na Unidade de Internação Pediátrica (UIP) de um hospital público de grande porte, localizado em Goiânia-GO. Para viabilizar a coleta de dados, foi criado um grupo de suporte denominado Grupo de Apoio a Pais e Familiares (GRAPF), com o objetivo de acolher a família das crianças hospitalizadas oferecendo apoio e informações.

A UIP pesquisada possui dois blocos de internações: a Clínica Pediátrica e a Unidade de Terapia Intensiva Neonatal (UTIN). A Clínica Pediátrica dispõe de 20 leitos e a média de ocupação diária é de doze leitos. A UTIN tem 10 leitos destinados ao cuidado de recém-nascidos graves e de alto risco que e, frequentemente, todos os leitos estão ocupados.

O GRAPF foi coordenado por duas enfermeiras e supervisionado, na organização e condução, por uma enfermeira, especialista em Dinâmica de Grupo, e outra, com experiência na atenção aos familiares de pessoas internadas em Unidade de Terapia Intensiva. O grupo funcionou regularmente no período de fevereiro a julho de 2010, em sala da própria UIP, com encontros vespertinos, uma vez por semana. Os encontros tinham duração média de uma hora, sendo dez minutos para o acolhimento e apresentação dos participantes, vinte minutos para o compartilhamento de experiências e vivências, dez minutos para orientações e informações e vinte minutos para o processamento das experiências compartilhadas e avaliação da sessão grupal.

Durante o período da coleta de dados, todos os familiares/ acompanhantes das crianças internadas foram convidados a participar do GRAPF. Vale destacar que, nesse estudo, consideramos família quem seus membros dizem que são, independentemente de laços sanguíneos ou grau de parentes$\mathrm{CO}^{(11-12)}$. No total, 34 sujeitos, que atenderam aos critérios de inclusão de ter idade igual ou superior a 18 anos, pertencer à família de uma criança hospitalizada na UIP do hospital investigado no período da coleta de dados e ter comparecido a pelo menos duas sessões do grupo, participaram da pesquisa, assinando o Termo de Consentimento Livre e Esclarecido.

Todos os encontros do GRAPF foram gravados e registrados em diário de campo e os dados foram obtidos pela transcrição das sessões, juntamente com os registros do diário de campo. Para analisar os fatos e fenômenos vividos no grupo foi usada análise temática ${ }^{(13)}$.

Para representar os familiares, foram atribuídos letras e números, a fim de preservar sua identidade e evitar exposição e constrangimento. Assim, cada familiar foi identificado pela letra $\mathrm{F}$ seguida por um número que varia de 1 a 34 (número de familiares que participaram dos encontros) e pela letra $G$ acompanhada do número da sessão a que se refere o depoimento citado. Logo, o depoimento do familiar número dois no quarto encontro do GRAPF foi identificado como F2G4.

Esse estudo foi elaborado e desenvolvido seguindo as recomendações propostas pela Resolução 196/96 do Conselho Nacional de Saúde e aprovado pelo Comitê e Ética em Pesquisa Humana e Animal de um hospital localizado em Goiânia-Goiás (protocolo 153/2009).

\section{RESULTADOS}

Foram realizados doze encontros do GRAPF com número de participantes variando de três a sete em cada encontro, com média de 4,7 pessoas por sessão. Os familiares foram principalmente as mães das crianças $(23 ; 67,6 \%)$, seguidas por tios (5; $14,7 \%)$, avós $(4 ; 11,8 \%)$ e pais $(2 ; 5,9 \%)$. Participaram do maior número de encontros do grupo os acompanhantes de crianças que permaneceram internadas por mais tempo.

A análise das sessões grupais permitiu a proposição das categorias "Distância da família: conflitos e dificuldades", "Situações de desgaste físico e emocional", "Enfrentando mudanças e frustrações" e "O grupo como estratégia para o cuidado", que fornecem, aos profissionais da saúde, subsídios para compreender o quão é complexa a experiência de "ter" e "conviver" com uma criança hospitalizada, como veremos a seguir.

\section{A. Distância da família: conflitos e dificuldades}

Alguns familiares se sentem abandonados e até esquecidos pela família. Muitas vezes, a pessoa que acompanha a criança 
no hospital precisa enfrentar sozinha, as dificuldades advindas dessa experiência:

O pai do neném abandonou eu e ele. Raiva. Tô sentindo raiva demais dele! Porque eu procurei ele pra me ajudar e ele não quer saber! (F31G7)

Às vezes eu fico assim, pensando que o pai dele não preocupa [...]. As vezes eu brigo em casa. Fico pensando assim: "Poxa, mas é só eu que tem que tá com ele?". (F28G11)

[...] eu queria ter, sabe, o apoio da minha família, do meu marido. Queria que ele me ajudasse! Infelizmente, a minha família, da minha parte, tá longe. O meu marido tá aqui em Goiânia, mas ele veio aqui só pra não falar que não veio, pra não fazer feio, sabe? (F13G12)

Nesse contexto, a criança e seu acompanhante, além de aprender a conviver com novas rotinas, precisam aprender a suportar a distância e saudade de pessoas queridas:

A falta da minha família tá muito difícil. (F18G6)

A gente fica assim, longe de casa, e a gente fica assim, com vontade de conversar com os amigos, com os parentes. Desabafar. (F22G8)

Eu não gosto é de tá longe da minha família, da minha filha, principalmente. E o que eu gosto é de tá próximo da minha família, filha, mãe, pai, esposo, sobrinho. (F26G12)

O fato de ter outros filhos compromete, ainda mais, o bem estar do acompanhante, pois, além de se preocupar com a criança enferma, ainda sente culpa por não estar ao lado das que ficaram em casa:

Tenho mais duas [filhas] em casa. Aí, eu fico aqui pensando nas duas que tá lá. (F22G6)

Tem o outro filho, tenho que ficar longe [...]. O que mais me dói também, é que [...] eu tenho um outro de seis aninhos. (F33G9)

Fica martelando na minha cabeça se minhas filhas tá bem, o quê que tá acontecendo dentro da minha família... Porque aqui eu não tô sabendo, né? (F11G12)

Quanto mais longo o período de hospitalização da criança, mais tempo o acompanhante precisa permanecer na UIP e maiores são as dificuldades enfrentadas no cuidado das crianças que ficaram no lar. Algumas mães revelaram que os filhos demonstram tristeza e ciúmes da criança enferma:

Mas o dia que eu não venho é mais porque a minha outra neném fica chorando. Igual hoje lá na minha irmã, ela ficou chorando: "você não vai ver o T [o filho internado], você vai ficar mais eu". (F7G2)
Quando eu tô arrumando as malas pra sair [...] pro hospital: "Ah! mãe, volta logo, viu? Vê se a senhora volta logo!". (F33G9)

Outra situação que corrobora para o sofrimento do acompanhante é não ter com quem deixar os demais filhos, enquanto cuida da criança hospitalizada. Nem sempre um membro da família pode assumir essa tarefa e, muitas vezes, as crianças precisam ficar sob os cuidados de vizinhos, conhecidos, amigos ou de pessoas contratadas especialmente para esse fim:

[...] tem que deixar o filho... Fica abandonado! [...] é difícil porque você acha que confia e, ao mesmo tempo, lá no fundo, você não tem aquela confiança! Não é o pai, não é a mãe, não é você quem tá lá. Aí você não sabe o que pode acontecer, entendeu? Então pra mim essa é a parte mais difícil de lidar. (F26G9)

[...] tem gente que cobra trinta reais pra cuidar do outro, outros cobra trinta e cinco! (F7G1)

\section{B. Situações de desgaste físico e emocional}

Os familiares revelaram que acompanhar a criança, durante a hospitalização, prejudica o sono e repouso, trazendo consequências físicas que podem comprometer sua saúde. Eles afirmaram sentir cansaço e falta de tempo para o cuidado de si mesmo:

Na hora que eu deitar pra dormir, acho que eu vou desmaiar, porque tem muito sono acumulado! (F29G12)

\section{[...] Aqui, a gente até que dorme, mas não é igual em casa!} (F22G8)

Fiquei 32 dias sem sair daqui! (F15G10)

Mal cheguei em casa, já tava vindo pra cá [...] não dá nem tempo pra gente dá uma arrumada, né? A gente esquece da gente e só lembra dos filhos. (F14G10)

Por todas as repercussões do processo de hospitalização na vida da família e da criança, são frequentes as manifestações de sentimentos negativos, como tristeza e angústia:

[...] tem hora que bate aquela tristeza, né? (F23G1)

[...] fiquei em desespero várias vezes! (F32G5)

A princípio, quando meu filho adoeceu, eu me senti assim: quatro paredes e uma porta fechada sem a chave. (F26G9)

[...] muito, muito abalada! Muito triste! Às vezes, eu fico [...], muito depressiva! (F28G11)

Eu não sei o que eu tô sentindo... Tô um peixinho fora dágua! Não tô sentindo os meus pés no chão. [...] ver minha 
filha assim, sabe? [chora]. Tô levando. (F9G12)

Além do desgaste físico e emocional, algumas mães ainda se sentem culpadas pela doença da criança:

[...] às vezes, eu fico assim, pensando que eu tenho culpa, sabe? [...] eu falei pro médico mesmo, se meu menino nasceu com esse problema, se eu era culpada. O médico falou que não. (F28G11)

\section{Enfrentando mudanças e frustrações}

Para ficar com a criança durante sua internação e atender às novas demandas, o acompanhante precisa modificar seus hábitos de vida diários. Dentre as situações geradoras de sofrimento, destaca-se o desejo de retomar as atividades interrompidas devido à sua permanência no hospital:

\section{Tá fazendo falta é a igreja. (F18G6)}

Aí, minha casa tá abandonada, meu cachorro tá passando fome. (F22G6)

\section{Eu não gosto é ficar longe da minha casa! (F3G11)}

Apesar das frustrações e do sofrimento gerado pelas mudanças e dificuldades vivenciadas pelos acompanhantes, alguns acreditam ter a obrigação de permanecerem firmes ao lado da criança, incentivando, ajudando e dando força. Eles acreditam que não podem demonstrar fraqueza, desesperança ou tristeza, pois ela está ali para apoiar, sem jamais esmorecer:

Hoje eu tenho que tá fingindo o tempo todo, sendo mais forte do que ela [chora]. É as máscaras, a gente tem que tá mascarado. (F5C8)

[...] mesmo que, às vezes, a gente olhe lá no fundinho e dá uma tristezinha, né, eu tenho que tampar ela [...], deixar [...] transparecer a alegria. (F33G11)

\section{[...] perto do meu menino, tenho que tá forte! (F14G10)}

\section{O grupo como estratégia para o cuidado}

Em seus depoimentos, os acompanhantes revelaram o quanto necessitam de um espaço para compartilhar sentimentos e informações e para oferecer e receber apoio de outras famílias e dos profissionais:

Eu gostei, porque eu desabafei. A gente desabafa [...], fala o que tá preso na garganta, né? Chorei. Foi bom! (F12G4)

[...] esclarece muita coisa, né, que as vezes a gente não sabe. [...] as vezes o neném tá passando por alguma coisa que a gente não sabe, né, aí esclarece pra gente! (F22G6)

[...] é como se fosse assim, uma família pra você dividir os sentimentos. Independente de quais são eles. (F33G11)

\section{DISCUSSÃO}

A hospitalização de um ente querido exige reorganização do sistema familiar e, para atender às demandas impostas pelo processo de adoecimento, a família, além de assumir novas atividades, também precisa adaptar-se à mudanças na rotina profissional, pessoal e social ${ }^{(5-6,9,14-15)}$. Na área pediátrica, apesar da hospitalização da criança influenciar a vida de todos os membros de sua família, cada pessoa envolvida nesse processo tem uma experiência singular diretamente relacionada às atividades assumidas pela mesma ${ }^{(5-6)}$.

A responsabilidade de acompanhar a criança durante sua internação hospitalar, experiência difícil que provoca desgaste físico e emocional, é comumente assumida pela mãe $\mathrm{e}^{(5-6,9)}$. Entretanto, o sistema familiar deve apoiar a criança e seu acompanhante, pois o fortalecimento dos laços afetivos é fundamental para que as pessoas envolvidas se sintam em condições de lidar com as nuanças advindas do processo saúde-doença e, pois, de enfrentar os momentos de dificuldades ${ }^{(7,9)}$. Quando o acompanhante recebe apoio da família, amigos, vizinhos ou representantes religiosos, ele se sente mais seguro e preparado para enfrentar essa experiência ${ }^{(7)}$.

Todavia, nem sempre o acompanhante pode contar com apoio familiar. Muitos sujeitos desse estudo se queixaram da solidão e isolamento social, sentindo-se distanciados de seu núcleo familiar e tendo que assumir, sozinhos, a responsabilidade de cuidar da criança ${ }^{(9,16-17)}$. Vale destacar que experiências vivenciadas no processo saúde-doença podem levar as pessoas a rever o significado do termo família, que deixa de estar vinculado a laços consanguíneos para ser expresso por meio do apoio recebido em meio ao sofrimento, ou seja, o significado de família, muitas vezes, se vincula ao ato de cuidar ${ }^{(12)}$. Assim, a doença e hospitalização podem levar a família a rever atitudes e fortalecer os vínculos, reformular relações e transformar a unidade familiar, ampliando ou, até mesmo, rompendo laços afetivos ${ }^{(9,18-19)}$

O problema de ausentar-se do lar fica ainda mais difícil quando o acompanhante tem que deixar outros filhos em casa, pois a interrupção do convívio com eles agrava seu sofrimento $^{(5-6,9,16)}$. E o sofrimento não é exclusividade dele, que se preocupa com as crianças que ficaram em casa ${ }^{(5-6)}$; os outros filhos também sofrem tanto pela ausência do irmão doente quanto da figura materna e, com o pai, não é diferente, pois além da impossibilidade de permanecer com o filho doente, ainda é privado da convivência com sua esposa/companheira e sobrecarregado pelas responsabilidades que eram compartiIhadas com a mesma ${ }^{(6)}$.

Nesse estudo, as mães colocaram claramente o dilema resultante de sua ausência do lar. Por um lado, os demais filhos sentem-se abandonados, preteridos e enciumados em relação à atenção dispensada à criança hospitalizada ${ }^{(9)}$; por outro, a mãe, além de sofrer pela distância, se angustia mais ainda quando precisa delegar a tarefa de cuidar dos filhos que ficaram em casa a pessoas em quem não sabe se pode confiar, tendo que conviver, também, com o medo, incerteza e insegurança, que aumentam seu sofrimento ${ }^{(5,9)}$. Elas se ressentem, ainda, da falta do suporte social que poderia ajudá-las a 
enfrentar esse sofrimento; da distância de outros familiares e amigos e da ausência de atividades sociais, que acentuam seu isolamento e solidão e contribuem para tornar essa experiência significativamente negativa(5-6,9,16-17).

Quase todas as mães entrevistadas manifestaram sentimentos negativos que frequentemente tomam conta delas. A literatura ressalta que o sofrimento pode assumir diferentes contornos, de acordo com o significado atribuído à doença e sua gravidade, à experiência de internação e às implicações dessa no dia-a-dia da família. Sentimentos como tristeza, desespero, angústia, preocupação e nervosismo podem ser usados para caracterizar a situação de acompanhar crianças hospitalizadas ${ }^{(5,9,17)}$. A mãe, quase sempre a acompanhante da criança, fica exposta a diversas situações geradoras de sofrimento psíquico, entre as quais o sentimento de culpa pelo surgimento da doença ou de suas complicações no filho ${ }^{(5,8)}$. Destaca-se, aqui, a responsabilidade da equipe de saúde em esclarecer a família sobre o diagnóstico e quadro clínico da criança, desmistificando o surgimento da enfermidade e buscando desfazer a associação entre doença e punição da mãe/família.

As normas e rotinas da unidade hospitalar constituem outro desafio para o acompanhante $\mathrm{e}^{(9,15-16)}$. Ele precisa aprender a enfrentar e aceitar os rituais de diagnóstico e tratamento e a desenvolver estratégias que o ajudem a suportar seu sofrimento diante do sofrimento da criança. Os sujeitos desse estudo acreditam que, independentemente do que estejam sentindo, devem ocultar a própria dor e mostrarem-se fortes para transmitir segurança e ajudar a criança em sua recuperação ${ }^{(9,16)}$. Nesse contexto, merece destaque o fato de várias UIP não serem dotadas de condições adequadas para acolher e manter o acompanhante. No campo pesquisado, o espaço físico é restrito e não há cama para o acompanhante, o que compromete seu sono e repouso, intensificando o desgaste físico ${ }^{(15)}$. Além da falta de conforto para o descanso, já que só dispõe de uma poltrona, o acompanhante ainda precisa adaptar-se a variados ruídos provenientes dos equipamentos e alarmes, bem como de conversas entre funcionários, tendo de manter-se atento a tudo que acontece com a criança e atender às suas demandas.

Todos esses aspectos configuram a tarefa de acompanhar a criança durante a internação hospitalar como difícil e estressante. Ao falar sobre a experiência de conviver com uma criança que necessita de cuidados de saúde, muitos familiares se mostraram bastante emocionados e incapazes de conter o choro. Essa fragilidade emocional confirma sua necessidade de apoio tanto por parte de seus familiares e de outras pessoas queridas como dos profissionais de saúde ${ }^{(5,9,11,20)}$. Portanto, esses profissionais precisam incluir a família em seu plano de cuidados, favorecendo seu convívio e promovendo ações que contemplem as singularidades do acompanhante, tais como escuta atentiva, respeito, construção de vínculo com a família e acoIhimento ${ }^{(5,8)}$. A equipe de saúde deve valorizar a história de vida de cada pessoa, suas histórias, valores, cultura e experiências, ajudando-a a compreender o contexto em que surgiu a doença e as maneiras de enfrentamento assumidas por cada pessoa.

Nesse cenário, o grupo de suporte apresenta-se como estratégia útil e viável para o oferecimento de apoio ao acompanhante. Compartilhando suas experiências com outras pessoas que vivem situação similar, a pessoa percebe que não é a única com essa dor e sente liberdade para expressar seus sentimentos, dificuldades, limitações, medos, ansiedades e incertezas, pois sente-se pertencente ao grupo e sabe que ali todos compreenderão do que está falando. Além disso, observando outros integrantes, a pessoa pode aprender novos comportamentos e formas de enfrentar a situação ${ }^{(8)}$. Na opinião dos sujeitos desse estudo, o atendimento em grupo é uma estratégia adequada para o atendimento das necessidades de informações e suporte emocional dos familiares de crianças hospitalizadas, colaborando para reduzir seu sofrimento e, assim, tornar o cuidado mais humanizado ${ }^{(8,20)}$. O grupo lhes proporcionou espaço para desabafar, dividir sentimentos e frustrações, receber e dar apoio a outros familiares em igual situação; em suma, no GRAPF eles se sentiram acolhidos e informados.

\section{CONCLUSÃO}

Os resultados dessa investigação demonstram que a hospitalização de uma criança interfere significativamente na vida de todos os familiares e, de maneira especial, na da mãe, que é a pessoa que, na maioria dos casos, acompanha a criança durante toda a sua internação. De modo quase consensual, verificou-se que essa situação afeta significativamente, como um todo, seu relacionamento familiar, sua saúde física e mental e a manutenção de sua rede social. O cansaço é acentuado pela falta de uma estrutura física adequada para seu repouso e pela necessidade de se manter continuamente alerta a qualquer alteração na condição clínica da criança além de atender as demandas específicas de cuidado.

A falta de apoio dos outros membros da família agrava o sofrimento e realça o isolamento social a que são submetidas as mães. Atualmente, mesmo com a facilidade para de obtenção de informações na área da saúde, algumas mães ainda se sentem culpadas pelo surgimento da doença da criança e se questionam a respeito de terem feito ou deixado de fazer alguma coisa que pudesse ter evitado o seu adoecimento. Assim, é necessário que os profissionais de saúde invistam no oferecimento de informações e esclarecimento das dúvidas dos familiares, com o objetivo de minimizar o sofrimento dessas pessoas. Entretanto, o que se observa na prática é que, apesar de vasta literatura recomendando estratégias para o cuidado da família que passa por essa experiência, ainda é comum encontrar profissionais que se preocupam exclusivamente com o cuidado da criança, em detrimento da assistência aos familiares.

Embora seja comum e frequente, o sofrimento dos familiares precisa deixar de ser visto pelos profissionais de saúde como normal e esperado no contexto hospitalar. É necessário que estes reflitam sobre sua prática e passem a se sentir inquietos e incomodados com essa situação ao ponto de se verem compelidos a procurar novas estratégias de atuação para mudar esse cenário. Se não se pode mudar a realidade da doença da criança e o sofrimento de seus familiares, pelo menos, que se faça algum esforço para amenizar as demais fontes de sofrimento para eles. Espera-se que os resultados desse estudo despertem nos profissionais de saúde a necessidade de redirecionar sua prática assistencial, passando a ver a família 
de seus pacientes também como alvo de seus cuidados.

No contexto da hospitalização pediátrica é indispensável que a equipe de saúde realize o diagnóstico das situações que corroboram para intensificar o sofrimento do acompanhante e, em resposta a esses diagnósticos, desenvolva intervenções que ajudem amenizar o sofrimento dessas pessoas. Para isso, eles precisam se dispor a ouvi-las, compreendendo e respeitando as singularidades de cada uma. Considerando o papel da academia na formação profissional, talvez um dos caminhos nessa direção seja os cursos de graduação na área da saúde começarem ou passarem a enfatizar a necessidade de assistência também à família, oportunizando aos graduandos trabalhar com essa clientela, de modo a introjetar esses valores em sua prática profissional.

\section{REFERÊNCIAS}

1. Uhl T, Fisher K, Docherty SL, Brandon DH. Insights into patient and family-centered care through the hospital experiences of parents. J Obstet Gynecol Neonatal Nurs 2013;42(1):121-31.

2. Carvalho JBL, Araújo ACPF, Costa ICC, Brito RS, Souza NL. Representação social de pais sobre o filho prematuro na Unidade de Terapia Intensiva Neonatal. Rev Bras Enferm 2009;62(5):734-8.

3. Thomazine AM, Passos RS, Bay Júnior OG, Collet $\mathrm{N}$, Oliveira BRG. Assistência de enfermagem à criança hospitalizada: um resgate histórico. Ciênc Cuid Saúde 2008;2(Suppl 1):145-52.

4. Pimenta EAG, Collet N. Dimensão cuidadora da enfermagem e da família na assistência à criança hospitalizada: concepções da enfermagem. Rev Esc Enferm USP 2009;43(3):622-9.

5. Oliveira RR, Santos LF, Marinho KC, Cordeiro JABL, Salge AKM, Siqueira KM. Ser mãe de um filho com câncer em tratamento quimioterápico: uma análise fenomenológica. Ciênc Cuid Saúde 2010;9(2):374-82.

6. Hayakawa LY, Marcon SS, Higarashi IH. Alterações familiares decorrentes da internação de um filho em uma unidade de terapia intensiva pediátria. Rev Gaúch Enferm 2009;30(2):175-85.

7. Côa TF, Pettengill MAM. The vulnerability experienced by the family of children hospitalized in a pediatric intensive care unit. Rev Esc Enferm USP 2011;45(4):824-30.

8. Santos LF, Oliveira LMAC, Munari DB, Peixoto MKAV, Silva CC, Ferreira ACM, et al. Grupo de suporte como estratégia para assistência de enfermagem à família de recém-nascidos hospitalizados. Rev Eletrônica Enferm 2012;14(1):42-9

9. Silva MAS, Collet N, Silva KL, Moura FM. Cotidiano da família no enfrentamento da condição crônica na infância. Acta Paul Enferm 2010;23(3):359-65.

10. Paim L, Trentini M, Madureira VSF, Stamm M. Pesquisa convergente assistencial e sua aplicação em cenários da enfermagem. Cogitare Enferm 2008;13(3):380-6.

11. Wright LM, Leahey M. Enfermeiras e famílias: um guia para avaliação e intervenção na família. 4. ed. São Paulo: Roca; 2008.

12. Sanchez KOL, Ferreira NMLA. Reorganização do sistema familiar na condição do câncer. Ciênc Cuid Saúde 2011;10(3):523-32.

13. Bardin L. Análise de conteúdo. Lisboa: Edições 70; 2010.

14. Fernández-Castillo A, Vílchez-Lara MJ, López-Naranjo I. Parental stress and satisfaction during children's hospitalization: differences between immigrant and autochthonous population. Stress Health 2013;29(1):22-30.

15. Bsiri-Moghaddam K, Basiri-Moghaddam M, Sadeghmoghaddam L, Ahmadi F. The Concept of Hospitalization of Children from the View Point of Parents and Children. Iran J Pediatr 2011;21(2):201-8.

16. Silveira AO, Angelo M, Martins SR. Doença e hospitalização da criança: identificando as habilidades da família. Rev Enferm UERJ 2008;16(2):212-7.

17. Costa JB, Mombelli MA, Marcon SS. Avaliação do sofrimento psíquico da mãe acompanhante em alojamento conjunto pediátrico. Estud psicol (Campinas) 2009;26(3):317-25.

18. Di Primio AO, Schwartz E, Bielemann VLM, Burille A, Zillmer JGV, Feijó AM. Rede social e vínculos apoiadores das famílias de crianças com câncer. Texto \& Contexto Enferm 2010;19(2): 334-42.

19. Araújo YB, Collet N, Moura FM, Nóbrega RD. Conhecimento da família acerca da condição crônica na infância. Texto \& Contexto Enferm 2009;18(3):498-505.

20. Liu CH, Chao YH, Huang CM, Wei FC, Chien LY. Effectiveness of applying empowerment strategies when establishing a support group for parents of preterm infants. J Clin Nurs 2010;19(11-12):1729-37. 